\title{
0 'Ethos' Nobiliárquico no final do Antigo Regime: poder simbólico, império e imaginário social
}

Nobiliary "Ethos" in the Dusk of the

Ancien Régime: Symbolic Power,

Empire and Social Imagery

Nuno Gonçalo Monteiro

Instituto de Ciências Sociais da

Universidade de Lisboa

\begin{abstract}
Resumo
Com este texto procura-se apresentar alguns aspectos marcantes do "ethos nobiliárquico" português do Antigo Regime como ponto de partida para uma avaliação, apenas brevemente esboçada, dos seus efeitos na modulação das sociedades da América portuguesa. Procura-se discutir em que medida os seus referentes remotos, retomados dos modelos dos guerreiros medievais mas consagrados na ordem jurídica e simbólica, constrangiam os comportamentos e os processos de estruturação social e em que medida estes os podiam transmutar, destacando-se o esforço da coroa para actuar como instância reguladora do acesso e reprodução dos estatutos nobilitantes.
\end{abstract}

\section{Abstract}

This text aims to discuss some aspects of the portuguese "nobiliary ethos" during the Ancien Régime, that discussion is made as a precondition to the evaluation - even if briefly sketched - of its effects and consequences in the plural society of Portuguese America. The author tries to access in each way ancient patterns, borrowed from the model of the medieval knights but consecrated in the legal and symbolic orders, not only could define behaviors and social structuration processes, but also how these - specially the Crown efforts to function as a regulatory instance of access and reproduction of the nobility - could, reversibly, change those patterns.

\section{Palavras-chave}

elites, Império português, Antigo Regime

\section{Keywords}

elites, Portuguese Empire, Ancien Régime 
Originariamente publicada entre 1835 e 1840

2

Algumas dos tópicos aqui desenvolvidos foram colocadas uma primeira vez na comunicação "0 imaginário nobiliárquico", apresentada no Congresso Portugal-Brasil/Ano 2000, que teve lugar no Instituto Geográfico e Histórico da Bahia, entre 22 e 24 de Novembro de 2000.

Nesse particular, destacaria, em especial, a minha sintonia com os esforços de alguma historiografia (e não só) para superar, ao mesmo tempo, a crise das grandes aproximações objectivistas e estruturalistas e os insuperáveis dilemas (para não dizer becos sem saida) para os quais tendem as posturas pós-modernas.

Cf. o clássico de G. Duby, Les trois ordres ou l'imaginaire du féodalisme, Paris, Ed. Gallimard, 1980.

5

António Hespanha, "Categorias. Uma reflexão sobre a prática de classificar", Análise Social, n¹68, 2003, p.827, texto em parte inspirado por um diálogo com Reinhardt Kosellek, Le futur du passé. Contribuition à la sémantique des temps historiques, Paris, Ed. E.H.E.S.S., 1990.
Antes mesmo da sua autonomia política, podemos já encontrar os primeiros autores que reflectiram e procuraram avaliar o impacto das instituições do Antigo Regime do velho continente nos processos de estruturação das sociedades construídas no Atlântico Americano. Num outro contexto e em direcção diversa, o livro clássico de Alexis Tocqueville Da democracia na América ${ }^{1}$ partiu do postulado radical da inexistência de nobreza nas colónias inglesas da América para sustentar o postulado da natureza matricialmente distinta das suas instituições democráticas. Embora me seja difícil apresentar um balanço global de uma matéria que só conheço de forma incompleta, creio que se pode afirmar que a reflexão brasileira sobre análogas questões, produto das análises de sucessivas gerações de historiadores e publicistas, tem partido de fundamentos opostos: é o impacto das instituições e das elites dirigentes luzas do Antigo Regime que se utiliza para explicar boa parte das características específicas da sociedade brasileira do porvir.

Os objectivos deste texto são mais modestos. Apresentam-se alguns aspectos marcantes do "ethos nobiliárquico" português do Antigo Regime como ponto de partida para uma avaliação, apenas brevemente esboçada, dos seus efeitos na modulação das sociedades da América portuguesa ${ }^{2}$. As linhas que se seguem têm, ao invés de um escrito sistemático, as caracteristicas de um conjunto de notas parcelares e de uma digressão algo errática sobre um tema quase inesgotável. Acresce que se privilegiaram, não os textos normativos, mas as práticas sociais e institucionais ${ }^{3}$. Tal como se procurou ${ }_{1}$ quando foi caso disso, sublinhar traços específicos e marcas singulares que diferenciavam a monarquia portuguesa de outros contextos. Finalmente, importa destacar que o texto retoma e resume muitos dos meus anteriores trabalhos, embora dentro de um enquadramento distinto.

As representações do mundo social dominantes em Portugal e no seu império no século XVIII concebiam a ordem social na hierarquia dos seus distintos corpos, sancionada pela tradição. Quer isto dizer que a mesma ordem social se legitimava pelo tempo e pela história, uma história com origens medievais incontornáveis. Com efeito, tinha como referente remoto a representação trinitária da sociedade, comum a todo o 0cidente 4 . Devem salientar-se, desde já, duas implicações decisivas desse referente originário e remoto sobre as sociedades europeias da época moderna, transpostas, com limites que adiante se discutirão, para as longinquas paragens das suas "conquistas".

Em primeiro lugar, importa não esquecer que durante todo o período medieval e moderno, a nobreza não era apenas uma dignidade, mas uma dignidade à qual correspondiam privilégios. Ora, desde os finais da Idade Média que esses privilégios foram sendo progressivamente institucionalizados, ou seja, consagrados e inscritos no direito, na ordem jurídica. Como recordou recentemente António Hespanha, «numa sociedade de classificações ratificadas pelo direito, como era a sociedade de antigo Regime, (esses) estatutos eram coisas muito expressamente tangiveis, comportando direitos e deveres específicos, taxativamente identificados pelo direito» 5 . Este facto, distingue já claramente o séc. XV e períodos ulteriores da primeira Idade Média. Na primeira dinastia portuguesa, os nobres (que não se designavam como tal) eram na época e são-no hoje (pela investigação) identificados sobretudo de acordo com as funções que desempenhavam (os que combatem, os que detêm poderes jurisdicionais, os que recebem 
Cf. , sobre o assunto os estudos decisivos de José Mattoso, em particular, Ricos-Homens, Infanções e Cavaleiros. A Nobreza Medieval Portuguesa nos Séculos XI e XII, 2a ed., Lisboa, Guimarães Ed.,1985, pp. 113 e seg. e 172 e seg.

Cf. Ellery Schalk, From Valor to Pedigree. Ideas of nobility in the sixteenth and seventeenth centuries, Princeton, Princeton Univ. Press. 1986.

\section{8}

A noção de "qualidade», central na cultura política das elites dos século XVII e XVIII, reportava-se à "qualidade do nascimento", ou seja, ao estatuto que cada um tinha antes mesmo de nascer. A definição do mais relevante tratado de nobreza de finais do Antigo Regime, segundo a qual a nobreza "é uma certa dignidade derivada dos pais, ou da concessão do Príncipe» (Luis da Silva Pereira Oliveira, Privilegios da nobreza, e fidalguia de Portugal, Lisboa, 1806, p.5), permite distinguir entre a nobreza natural, que derivava da "qualidade de nascimento", e a nobreza adquirida por outras vias.

Cf. João Pinto Ribeiro, "Preferencia das Letras às Armas», in Obras varias..., $1^{\text {a }}$ parte, Coimbra, 1730.

\section{0}

A questão é demasiado relevante e complexa para poder ser discutida aqui. Sublinhem-se apenas duas ideias gerais: até meados do século XVII venderam-se em Portugal ofícios e estatutos superiores com bastante frequência (senhorios, ofícios destacados nas alfândegas, etc.) o que depois praticamente deixou de se verificar; no império manteve-se até tarde, com mais frequência do que no reino, a venda de ofícios menores quanto ao estatuto, mas não quanto ao rendimento. determinadas delegações da realeza, etc.). Já não era assim no século XVI, nem mesmo, em rigor, no século XV. A taxinomia da Alta Idade Média - ricos-homens, infanções e cavaleiros ${ }^{6}$ - foi substituída nos derradeiros séculos medievais por uma nova classificação - fidalgos, cavaleiros e escudeiros - que espelhava a difusão do ideário cavaleiresco e acentuava já a dimensão de hereditariedade sugerida pela semântica do vocábulo fidalgo (hijo de algo, retomado das célebres Siete Partidas de Afonso X). Como em muitas outras paragens 7 , a nobreza corresponderá cada vez menos a uma função, para passar a ser cada vez mais uma "qualidade» 8 . E, no entanto, o ideal nobiliárquico (apesar de se conceder às letras direitos indiscutiveis ${ }^{9}$, mais tarde alargados a outros âmbitos) mantém-se sempre prisioneiro desse referencial originário e fundador, em larga medida associado a funções militares.

Em seguida, deverá recordar-se que durante séculos e de forma descontínua, as monarquias travaram um combate para controlar a definição dos diferentes estatutos e das diversas classificações (embora nunca tivessem conseguido deter o exclusivo que procuraram alcançar). 0 acesso aos diversos graus de nobreza constituia, nesse terreno, um recurso de poder fundamental das monarquias. As monarquias instituíram, com efeito, sistemas de remuneração de serviços. Em muitos casos, recorreram também à venda de ofícios nobilitantes, o que, no entanto, não se verificou em Portugal a não ser numa escala reduzida ${ }^{10}$. Através destes processos podiam conceder aos seus súbditos, não apenas beneficios materiais vários, mas ainda as tão procuradas honras e distinções. Note-se, porém, que este combate pela instauração do monopólio régio das classificações sociais não corresponde linearmente a uma "centralização" e menos ainda a uma governamentalização, como adiante se procurará destacar.

As mudanças verificadas posteriormente na hierarquia das nobrezas inseriram-se no quadro de um esforço descontínuo da monarquia para controlar o vocabulário social e a delimitação dos estatutos (o poder de classificação), bem como para potenciar esse recurso no quadro da remuneração dos serviços que the deviam ser prestados. Nesse processo, o século $X V$, com a concessão dos títulos novos, a Lei Mental e a criação das matrículas da Casa Real, constituiu um momento importante. De facto, a partir da dinastia de Avis (1385-1580), a Coroa passou a utilizar de forma continuada diversos dispositivos que se revelaram fundamentais na hierarquização interna do grupo e que se mantiveram até 1832 (data do triunfo da revolução liberal), apesar dos abalos sofridos durante o pombalismo e em outros momentos. Entre esses dispositivos estão a titulação e a outorga de senhorios (jurisdicionais ou não), reforçada no quadro da já referida Lei Mental, que em teoria podia permitir a reversão dessas concessões. A Coroa passou ainda a dispor de recursos mais amplos para actuar como instância de distribuição e redistribuição de honras e proventos com a definitiva incorporação em 1551 da administração das três ordens militares de Avis, Cristo e Santiago. Se a concessão de hábitos foi fundamental na base da pirâmide nobiliárquica para regular a atribuição do estatuto de cavaleiro, a distribuição das comendas (mais de seis centenas, ao todo) constituiu uma componente essencial da reestruturação do topo. Por fim, os excepcionais recursos, em fontes de rendimento e em ofícios, fornecidos pela expansão colonial africana e asiática (só mais tarde, brasileira) completam a enumeração dos dispositivos de que a Coroa dispunha enquanto instância de regulação do espaço social nobiliárquico. 
António M. Hespanha, «A Nobreza nos tratados Jurídicos dos séculos XVI a XVIII!, Lisboa, Penélope. Fazer e desfazer a história, Lisboa, ed. Cosmos, no12, 1993, p.28.

\section{2}

Que constituiriam na sociedade medieval uma categoria restrita, abrangendo ainda em finais da Idade Média segundo algumas estimativas (cf. p.ex., A.H. de Oliveira Marques, "Nobrezaépoca medieval», in Joel Serrão (...) Dicionário de História de Portugal, Lisboa, Iniciativas Editoriais, s.d.) cerca de 1\% da população.

13

A.M. Hespanha, idem, ibidem.

14

P. J. Mello Freire, "Instituições do direito civil português", livro segundo, tit. III, in Boletim do Ministério da Justiça, Lisboa, n¹63, 1967 (tradução de M. P. Menezes), p.44.

\section{5}

Cf. , entre outros, Carlos Silva Lopes, Ensaio sôbre a nobreza portuguesa (sep. da «Nação Portuguesa», serie V), Lisboa, 1929, e Nuno Gonçalo Monteiro, "Notas sobre nobreza, fidalguia e titulares nos finais do Antigo Regime", Ler História, Lisboa, nº 10, 1987.

\section{6}

Cf. , entre outros: Alvaro Balthazar Alves, "0 Cartório da Nobreza", Anais das Bibliotecas e Arquivos de Portugal, Lisboa, vol. I, n4, 1915; Conde de São Payo, Do Direito heráldico Português, Lisboa, 1927; e Luis Bivar Guerra, Facilidades na habilitação para a Ordem de Cristo no século XVII (sep.), Tomar, 1949; e Luis Farinha Franco, "Les officiers d'armes (rois d'armes, herauts et suivants) et les reformateurs du greffe de la noblesse XVIle-XVIIle siècles", Arquivos do Centro Cultural Português, Paris, vol.XXVI, 1989.

17

As provas de nobreza só se difundem na Península Ibérica no século XVI e em França no século XVII.
Pode discutir-se, além disso, se entre esses dispositivos cabe ou não considerar a forma peculiar como a categoria jurídica de nobreza foi incorporada no direito português. É indesmentivel que esta circunstância acabou por potenciar os recursos da coroa. Um texto publicado há cerca de uma década por António Hespanha acrescenta alguma coisa à história jurídica e textual de um facto com perenes implicações na configuração da sociedade e da hierarquia nobiliárquica portuguesas. No período medieval e ainda nas Ordenações do reino, o termo nobreza era escassamente utilizado: «na classificação legal, existia (...) uma categoria de peão, a que se opunham distintas categorias privilegiadas»"11. Por outro lado, retomado das célebres Sete Partidas, o termo mais comum para designar as categorias nobiliárquicas em finais da Idade Média era o de fidalgo, associado aos defensores dos três estados em que Deus dividira o mundo, e, assim, às virtudes cavalheirescas, à perícia militar e à boa linhagem, ou seja, àqueles que descendiam, em princípio, dos vários ramos das linhagens constantes dos célebres livros medievais portugueses. Quer dizer, o ponto de partida seria, por um lado, a distinção legal entre peões e privilegiados e, por outro, a distinção no plano das representações socialmente marcantes entre os fidalgos $^{12}$ e os demais. Ora, "segundo o direito romano os homens ou são nobres ou plebeus" e "esta distinção passaria para o direito comum». Desta forma, nos primórdios da época moderna, "no plano das taxinomias textuais, a emergência da categoria «nobre" pode ser descrita como a recepção pela literatura jurídica de uma oposição bi-polar existente na literatura do direito comum italiano»13. Na prática social e institucional, esse processo de incorporação acabou por se traduzir a médio prazo na adopção de uma noção excepcionalmente ampla de nobreza, distinta da fidalguia, categoria sempre mais restrita. A nobreza passou a incluir, assim, uma grande diversidade de oficios e funções, diversas das tradicionais. Um destacado jurista de finais do Antigo Regime, Mello Freire, dirá a esse respeito: "sobrevivendo melhores tempos em que arrefeceu o furor bélico, acabou-se por dar a devida honra aos ofícios e cargos civis, surgindo outro género de nobres, que se não podem chamar propriamente Cavaleiros nem Fidalgos, mas gozam de todos os seus privilégios e direitos» ${ }^{14}$. A singularidade dessa categoria jurídica já foi há muito realçada ${ }^{15} \mathrm{e}_{\text {, ao contrário }}$ do que às vezes se escreve, constitui uma marca especifica portuguesa. Traduziu-se numa especifica estrutura nobiliárquica, que adquiriu as suas expressões paradigmáticas nos finais do Antigo Regime. Genericamente, poderiamos distinguir uma categoria ampla de nobres, com fronteiras fluidas; um grupo bem mais restrito de fidalgos, que cada vez mais tendiam a confundir-se com os matriculados na casa real; e, por fim, a primeira nobreza da corte, com os Grandes à cabeça. Mas a realidade social é bem mais complexa do que esse esquema elementar.

Parte integrante e essencial da institucionalização das honras e distinções, os diferentes graus de nobreza passaram a estar, cada vez mais, sujeitos a regras de acesso e de prova (brasões de armas, hábitos das ordens, filhamentos da casa real, acesso à governança das terras, elitização no acesso às distinções superiores) ${ }^{16}$, ainda que essa prova se pudesse resumir simplesmente a "viver nobremente com bestas e criados" ou, como então se dizia, "tratar-se à lei da nobreza". Tudo passou a ser cada vez mais regulamentado e a coroa esforçou-se, embora de forma descontínua, por controlar o acesso a esses estatutos. Fenómeno que, de resto não tinha nada de especificamente português ${ }^{17}$, e adquiriu expressões paradigmáticas 
Cf. sintese de Juan Hernandez Franco, "Pruebas de limpieza de sangre», in A. Molinié Bertrand e Pablo Rodríguez (eds.), Através del tiempo. Diccionario de fuentes para la historia de la familia, Murcia, Univ. de Murcia/U. E. de Colombia, 2000.

\section{9}

Cf. sobre o assunto Maria Inês Versos, "O valor da linhagem e do real serviço. 0 acesso ao grau de cavaleiro da Ordem Religiosa e Militar de S.João de Malta e o arquétipo de fidalgo em Portugal nos finais do Antigo Regimen, in As Ordens Militares e as Ordens de cavalaria na Construção do Estado Moderno Ocidental Actas do IV Encontro sobre Ordens Militares, Lisboa, Ed. Colibri,2005, pp.827-870, e, num âmbito mais geral, A. Sapagnoletti, Stato, aristocracie e Ordine di Malta nell' Italia Moderna, Roma, Ed. E. F. R., 1988.

\section{0}

Cf. em particular, no que se reporta à três ordens militares incorporadas na coroa o trabalho fundamental de Fernanda Olival, Honra, Mercê e Venalidade: as Ordens Militares e o Estado Moderno, Lisboa, Estar, 2001.

\section{1}

Cf. Nuno G. F. Monteiro, 0 Crepúsculo dos Grandes. A casa e o património da aristocracia em Portugal (1750-1832), Lisboa, Imprensa Naciona/Casa da Moeda, 1998, pp.545-550.

\section{2}

Idem, ibidem, p.29.

\section{3}

Cf. Nuno Gonçalo F. Monteiro, "0 "ethos» da aristocracia portuguesa sob a dinastia de Bragança. Algumas notas sobre a casa e 0 serviço ao rein, Elites e Poder. Entre o Antigo Regime e o Liberalismo, Lisboa, Imprensa das Ciências Sociais, 2003, pp.83-104.

\section{4}

Sobre o impacto da legislação pombalina na matéria, veja-se por todos o trabalho seminal de Jorge Pedreira, Os homens de negócio da praça de Lisboa de Pombal ao vintismo (1755-1822), dis. dout. mimeo., Lisboa, Univ. Nova de Lisboa, 1995. nos casos ibéricos numa outra prova, por vezes mais difícil de ultrapassar (a da pureza de sangue ${ }^{18}$ L- , e que na época moderna teve a sua expressão europeia na ordem religiosa e militar da cristandade católica, a Ordem internacional de S.João de Jerusalém de Malta ${ }^{19}$. A nobreza passou a ter de ser provada, embora, como veremos, em muitos casos houvesse formas de contornar as dificuldades que tal representava 20 .

A transformação da nobreza numa "qualidade», em larga medida herdada e passível de comprovação, por um lado, e o recurso da monarquia à atribuição dos diversos graus de nobreza para remunerar serviços, por outro, constituiram sempre duas dimensões que podiam contrapor-se e colidir entre $\mathrm{si}^{21}$. Teoricamente, a monarquia poderia utilizar esse mecanismo fundamental para subverter as hierarquias estabelecidas. $E_{1}$ com efeito, em alguns contextos essa tensão não deixou de se manifestar, designadamente, na base da pirâmide nobiliárquica: as distinções nobiliárquicas inferiores (cartas de brasões de armas, cavaleiros de ordens militares, designadamente) foram-se vulgarizando com as inerentes implicações. No caso português, o conflito pombalino entre a monarquia e a genealogia - contra a qual se abriu uma guerra declarada, associada à queima das listas de cristãos-novos e à questão das famílias puritanas - constitui uma expressão paradigmática dessa possibilidade 22 . No entanto, esses conflitos não ocorreram de forma sistemática e importa perceber porquê: a possibilidade de prestar serviços relevantes era condicionada pelo acesso aos ofícios que conferiam oportunidades para tal; ora, entre os critérios de escolha para esses ofícios foi pesando cada vez mais até meados do século XVIII, precisamente, a "qualidade» de nascimento. Ou seja, o sistema tendeu, pelo menos ao nível do topo, para funcionar em circuito fechado, contribuindo a remuneração dos serviços mais destacados, tendencialmente a partir de meados de seiscentos, para reforçar as hierarquias e as casas estabelecidas ${ }^{23}$. Apesar do abalo sofrido durante o pombalismo, o essencial manteve-se em pleno século XIX.

$\mathrm{Na}$ base da hierarquia social, as coisas terão sido algo diversas, como se disse. A legislação da monarquia favoreceu o "alargamento da nobreza», a definitiva compatibilização de muitas funções (designadamente, as actividades mercantis de grosso trato ${ }^{24}$ ) com esse estatuto, e a inserção de novos grupos nas teias do sistema remuneratório da monarquia. Não sem forte resistências, pois, como veremos, a ordem legal e as representações socialmente dominantes dos estatutos não eram realidades necessariamente coincidentes.

$\mathrm{Na}$ verdade, apesar dos poderes invocados pela realeza (não poucas vezes em declarado conflito com as implicações desse preceito essencial) importa relembrar, como antes se disse, a matriz corporativa e trinitária da ordem social e juridica prevalecente. Tratava-se de uma ordem natural, cuja configuração devia ser imediatamente apreensível. Por isso, os poderes e as hierarquias legados pela história reforçavam-se e legitimavam-se na medida em que podiam ser olhados e ouvidos. Daí a enorme importância de que se revestiam os rituais de afirmação e de visualização desses poderes, como as procissões, os autos de aclamação, etc. As representações e encenações das hierarquias sociais e dos poderes compreendiam uma relevância indiscutivel que não tem paralelo com as das sociedades contemporâneas.

Numa reflexão sumária acerca do peso desses constrangimentos seculares sobre as identidades nobiliárquicas, prisioneiras desse legado remoto, destacar-se-iam sobretudo quatro dimensões. 
25

Cf. F. Olival, op. cit.

26

Traduzida para português em 0 Portugal de D.João V visto por três forasteiros (tradução, pref. e notas, de Castelo Branco Chaves), Lisboa, Biblioteca Nacional, 1983, p.76, onde é atribuida a Merveilheux.

27

Idem, p.270

28

Veja-se, por exemplo, José Augusto França, 0 retrato na arte portuguesa, Lisboa, Livros Horizonte, 1980

\section{9}

Cf. Luis Bivar Guerra, Inventário e sequestro da casa de Aveiro em 1759, Lisboa, Tribunal de Contas, 1952, p.17

\section{0}

Atribuida o Conde de S.Lourenço e cit. em Cf. Nuno G. F. Monteiro, 0 Crepúsculo..., pp.24.

\section{Constrangimentos}

Em primeiro lugar, que o peso e os constrangimentos decorrentes da herança medieval, antes referida, não deixavam de ser bastante efectivos e persistentes. Desde logo, a hierarquia nobiliárquica foi designada até ao fim do Antigo Regime, em grande medida, por uma taxinomia militar medieval. Como antes se disse, o esquema de classificação da Baixa Idade Média fidalgos, cavaleiros e escudeiros -, que espelhava a preservação do ideário cavaleiresco, manteve-se até final do Antigo Regime, embora coexistindo com outros quadros de classificação.

A utilização, quase universal pelas elites portuguesas, das insignias da cavalaria das ordens militares, que se estendia à própria realeza, traduz de forma exemplar o peso dessa matriz cavaleiresca, evidente ainda no início do século XIX. Até ao fim, a sociedade das elites representava-se como um mundo de cavaleiros. Os respectivos símbolos tiveram em Portugal e no seu império uma difusão e relevância dificilmente igualáveis, ao mesmo tempo que os diversos estatutos por elas atribuídos (designadamente, os graus de cavaleiro e de comendador), bem como os proventos que podiam originar, adquiriram uma importância decisiva na configuração das categorias nobiliárquicas, a níveis diferentes e, de algum modo, contrapostos.

Os indicadores disponiveis a esse respeito são todos concordantes. Se os hábitos completos tinham um uso mais ocasional, era espantosa a difusão das insignias das ordens, sobretudo das de Cristo, utilizadas em quase todas as cerimónias e acontecimentos públicos por um leque tão amplo de personagens que surpreendia a maioria dos visitantes estrangeiros ${ }^{25}$. A este respeito possuimos muitos testemunhos, por exemplo, para os anos vinte de setecentos. Na anónima Discrition de la Ville de Lisbonne, que se reporta a 1728, observa-se o seguinte: «O Rei e a maioria da nobreza e fidalguia usam a ordem de Cristo, que está tão envilecida que a ostentam muitos oficiais subalternos e até comerciantes, empregados e cirurgiões, etc., podendo afirmar-se que hoje em Portugal o acesso a tais distinções é tão vulgar quanto noutro tempo era difícil alcançá- las» ${ }^{26}$. E, por volta de 1730, diz-se o mesmo numa das cartas de César de Saussure: "Nem só o rei, os príncipes de sangue e grande número de fidalgos são cavaleiros da Ordem de Cristo; são também uma infinidade de gentis-homens, de oficiais e até de comerciantes. Usam uma cruz de ouro ou prata dourada pendurada ao pescoço por uma fita vermelha. Surpreende-me que o rei e os príncipes de sangue ousem ostentar esta ordem que até certo ponto se pode considerar aviltada pelo grande número de pessoas de todas as classes que a possuem» 27 . 0 mesmo, que é, afinal, testemunhado pelos retratos: é difícil encontrar um quadro ou uma simples gravura de um personagem leigo português do século XVII até principios do XIX em que o retratado, seja ele um infante ou um financeiro, não ostente as insignias da ordem de Cristo ou de Santiago ${ }^{28}$. Tal como não será fácil descobrir um inventário de um membro das elites sociais da época em que não apareça pelo menos um hábito, com a diferença que os dos Grandes podiam ser "guarnecidos com diamantes brilhantes» 29 . E quando o corpo do primeiro fidalgo do reino, o $1^{\circ}$ Duque de Cadaval, foi a sepultar em 1727, com uma pompa com poucos precedentes, o hábito que trazia por cima de todos os mais era 0 da Ordem de Cristo. 0 ponto máximo dessa vulgarização parece ter-se atingido em Portugal no início de oitocentos, quando se chegou a produzir a célebre afirmação segundo a qual os usos destas insígnias «em muito poucos anos reduzem os três milhões de habitantes a três milhões de nobres» ${ }^{30}$. E, no entanto, nem mesmo nessa altura deixaram os membros da família real ou da primeira nobreza do reino de ostentar as referidas distinções. 
31

Cf. Evaldo Cabral de Mello, 0 Nome e o Sangue. Uma fraude genealógica no Pernambuco colonial, São Paulo, Companhia das Letras,1989.

32

Cf. F. Olival, op. cit., pp. 458-459.

33

Cf. F. Olival, op. cit..

34

Cf. as indicações de Luiz Felipe de Alencastro, 0 Trato dos viventes. Formação do Brasil no Atlântico Sul, São Paulo, Companhia das Letras, 2000, pp.302-307

35

Cf. Pedro Puntoni, A guerra dos Bárbaros. Povos indigenas e a colonização do sertão nordeste do Brasil 1650-1720, São Paulo, Ed. Hucitec, 2002.
Ao que tudo indica, essa procura estendeu-se com maior contenção ao império. As diversidade regionais, designadamente no Brasil, parecem ser notórias. 0 caso de Pernambuco, exemplarmente estudado por Evaldo Cabral de Mello, não é possivelmente passivel de generalização ${ }^{31}$. Contudo, a procura das distinções da monarquia não deixou de revestir um carácter geral. Certo é que, conforme demonstrou Fernanda Olival, entre 1700 e 1789 seriam lançados no Brasil 8,8\% dos hábitos de cavaleiro da Ordem de Cristo, quase 0 dobro do que se verificara nos sessenta anos anteriores 32 .

Esta extrema generalização dos graus e dos símbolos das ordens tem, desde logo, uma grande implicação. Precisamente pela enorme difusão dos hábitos, os cavaleiros nunca parecem ter chegado a constituir em Portugal um grupo corporativo. Essa dimensão esteve sempre, naturalmente, ausente, ao contrário do que se verificou em outras paragens. Porém, apesar da sua relativa vulgarização, sabemos que não desapareceu de modo algum o prestígio que tinham os simbolos das ordens militares. Pelo contrário, mantiveram sempre uma importância fulcral nos rituais da monarquia. Monarquia essa que integrou as ordens nas suas instituições e nas suas lógicas de remuneração de serviços. Nessa matéria, a realidade portuguesa não se distingue significativamente da evolução verificada em outras monarquias e estados europeus.

De resto, não obstante a proclamada equiparação ou preferência das letras às armas, estas nunca deixaram de ser privilegiadas nos imaginários nobiliárquicos. Os serviços feitos na "guerra viva» nunca tiveram equivalente.

Os serviços militares foram uma via decisiva para se receber mercê de um hábito de cavaleiro de uma ordem militar e, em particular até 1765 (quando foi abandonada), os prestados no Norte de África na praça de Mazagão. Conforme se colhe na recente investigação de Fernanda Olival, essa circunstância e o facto dos beneficiários serem muitas vezes militares com escassos recursos, alimentou um intenso mercado de compra e venda (encoberta por renúncia) de hábitos ${ }^{33}$. A extensão do conceito de "guerra viva" ao Brasil, sobretudo no século XVII, não deixou de constituir um problema ${ }^{34}$. Embora a questão mereça uma ampla investigação, parece certo que as "guerras dos bárbaros" na América não podiam ter o mesmo estatuto remuneratório que os feitos bélicos que se travavam em outras paragens ${ }^{35}$. Em geral, as representações dominantes e até as tabelas de remuneração dos serviços quedavam-se prisioneiras dos momentos fundadores, nos quais o Norte de África e depois a Índia tinham um peso já não coincidente com a sua importância económica e política em meados de seiscentos e depois.

Os serviços militares eram ainda mais relevantes no que se refere aos membros da primeira nobreza do reino. Com efeito, desde a Restauração de 1640 que o facto destes terem sustentado a dinastia de armas na mão nos seus momentos fundacionais constituia parte integrante e fundamental do pacto que julgavam ter estabelecido com a monarquia e que esta reconhecia como fundamento para a perpetuação do seu estatuto, contra ventos e marés. Na verdade, aceitou a obrigação de preservar e perpetuar as casas que tinham ajudado a consolidar a dinastia no seu período fundacional, sobretudo as que the tinham prestado serviços na "guerra viva", aos quais se atribuía uma relevância única. Mais exactamente, essas obrigações eram assumidas como dimensões "constitucionais» do regime brigantino, como um pacto tácito (e algumas vezes explícito), quase invariavelmente 
36

I.A.N./T.T., Ministério do Reino, Decretos, maço $58, n^{\circ} 63$.

37

Cf. Nuno G. Monteiro, 0 Crepúsculo..., p.524

38

Cf. «Poderes e circulação das elites em Portugal 1640-1820", in Elites e Poder..., pp. 105-138.
39

Cf. Nuno G. F. Monteiro, «Trajectórias sociais e governo das conquistas. Notas preliminares sobre Vice-Reis e Governadores-Gerais do Brasi e da İndia nos séculos XVII e XVIII), in J. Fragoso, M. F. Bicalho e F. Gouveia (orgs.), O Antigo Regime nos Trópicos. A Dinâmica Imperial Portuguesa (Séculos XVI-XVIII) (pref. de A. J. R. Russell-Wood), Civilização Brasileira, Rio de Janeiro, 2001, pp. 249-283.

40

Diogo Guerreiro Camacho de Aboim (16611709), Escola moral, politica, christã e juridica, Lisboa, 1747, p.206.

41

Op. cit., p.210. aceite pelas instituições da monarquia, entre a dinastia e as casas aristocráticas que na guerra a tinham defendido e sustentado. Cite-se apenas um exemplo, de resto conhecido. Quando em 1796 D. José da Costa, Marechal de Campo e futuro $6^{\circ}$ Conde de Soure, pediu a renovação na sua pessoa do título e demais bens da coroa e ordens da casa em que sucedera ao irmão, invocou, antes dos seus próprios, os «relevantes serviços feitos à Coroa destes Reinos, e ao Estado" pelos seus predecessores: «sendo conferido o título de Conde de Soure, e a maior parte dos bens da Coroa e Ordens, que possuía a Casa, ao $3^{\circ}$ Avô do Suplicante D. João da Costa, já pelos serviços de Aclamador, e Aclamador circunstanciado, já pelos serviços de General, e General vencedor, (...) como finalmente pelos serviços d'Embaixador (...) e sendo não só por estes respeitos continuados os ditos bens aos Condes de Soure seus sucessores, mas ainda acrescentados por outros serviços não só políticos, mas também militares, igualmente relevantes, feitos por mar e terra, também em Campanha viva, com distinção e louvor». Ora, acrescenta, «houve V. Majestade por bem declarar, (...) que as honras, e mercês que tinham entrado nas Casas em remuneração de Serviços feitos em guerra viva, continuassem nos Sucessores das mesmas Casas, ainda que fossem transversais» 36 .

De resto, não se tratava apenas de um pleito rendido aos momentos iniciais da dinastia. Uma esmagadora maioria dos Grandes (uma maioria cada vez mais ampliada ${ }^{37}$ ) e de membros da primeira nobreza prestou serviço no exército (quando tal não aconteceu isso foi dificilmente aceite) desde a Restauração até 1832. Acresce que os aristocratas da corte se mantiveram amplamente majoritários nos quadros superiores da instituição até finais do século XVIII38.

Aliás, foi essa tradução exemplar do persistente ethos militar da aristocracia portuguesa que fez com que até ao início de setecentos o vice-reinado na Índia mantivesse um certo precedente sobre o do Brasil, cujo estatuto nunca o superou até ao pombalismo: ao contrário deste, aquele era um governo dominantemente militar, no qual se podiam espeIhar heróica e recorrentemente os impetos bélicos dos fidalgos Grandes do reino que o exerceram ${ }^{39}$. Ainda que devedor de uma investigação aprofundada, importa salientar quanto a este aspecto que, de resto, os feitos heróicos na Índia se acrescentavam ou substituiam aos do período medieval no imaginário bélico da fidalguia portuguesa. Num dos textos fundamentais da moralistica portuguesa, editado postumamente em meados de setecentos, escrevia-se na lição "Da Pátria»: "para que andamos mendigando exemplos estrangeiros, quando em casa temos tantos, (...) baste referir os Governadores da Índia, que por amor da Pátria, e serviço do Rei se desterraram dele, levando seu nome às mais remotas partes do mundo" 40 . Em seguida, prosseguia o desembargador Diogo Guerreiro Camacho de Aboim, autor do citado texto, na enumeração detalhada dos feitos militares de todos os governadores e vice-reis da Índia quinhentista até ao segundo vice-reinado de D.Luis de Ataíde, Conde de Atouguia, "a quem chegou a noticia da perda del-Rei D.Sebastião em África, a morte del-Rei D.Henrique, e como aqui se acabou com a liberdade da Pátria aquele antigo valor dos Portugueses, que desanimados com o Governo de Castela, continuam mais frouxamente o governo daquelas Fortalezas, e serviço da Pátria». E concluía: "escusemos também de continuar com os Governadores, que se seguiram» 41 . 
42

Annal Indico Historico do Governo do (...) Senhor Marquez de Tavora..., Lisboa, 1754.

43

I.A.N./T.T., Casa Fronteira e Alorna, maço n¹22; publicado em Nuno Gonçalo Monteiro (selecção, introdução e notas), Meu pai e muito senhor do meu coração. Correspondência do Conde de Assumar para o seu pai, o Marquês de Alorna Vice-rei da Índia (1744-1751), Lisboa, Ed. Quetzal, 2000, p.92.

44

Cf. entre muitos outros estudos recentemente publicados, Fernando Dores Costa, "A nobreza é uma elite militar? 0 caso Cantanhede-Marialva 1658-1665" in Nuno G. F. Monteiro, Pedro Cardim e Mafalda Soares da Cunha (coord.), Optima Pars. Elites Ibero-Americanas do Antigo Regime, Lisboa, Imprensa das Ciências Sócias, 2005, pp. 167-190

45

Cf. Nuno G. F. Monteiro, 0 Crepúsculo..., pp.248249.
Em finais de seiscentos, como muitos anos depois, era aos governadores e vice-reis quinhentistas que se iam buscar os exemplos máximos da heroicidade lusitana. Mas, depois de 1580, detinha-se a narrativa. Ainda se combatia na Índia, no entanto, e, com o declínio da praças do Norte de África, pode-se até afirmar que já quase não existia outro campo de batalha onde continuadamente se pudessem fazer heróis. 0 Estado da Índia, frequentemente deficitário, vivia da memória dos feitos passados, mas também da possibilidade que abria à acção de novos Gamas, Almeidas e Albuquerques. No auge da sensibilidade barroca, nos finais do reinado joanino, exactamente quando se publica o texto antes citado, o vicereinado indiano parece ganhar novo alento. Senhores de casas da primeiríssima Grandeza do reino aceitam ir para lá. E é nessa altura que mais se celebram, através de publicações impressas, todos os seus feitos e cometimentos, sistematicamente equiparados aos dos heróis quinhentistas. Antes de mergulhar numa obscuridade de mais de dois séculos, a Índia Portuguesa conheceu, assim, o seu último momento de glória, pelo menos no imaginário lusitano. Os últimos vice-reis joaninos eram todos marqueses e viram todos os seus mais pequenos passos rodeados de uma celebração sem precedentes. Louriçais, Alornas e Távoras deram à Índia lusitana esse último alento bélico e fidalgo, pois, como se dizia a propósito das "heróicas proezas dos esclarecidos Tavoras", "cansada já a mesma Fama de publicar o destinado Valor, que dos Heróis desta Regia família se propaga, foi preciso dar-Ihe novo» ${ }^{42}$.

Até que ponto aqueles sentimentos eram partilhados e assumidos podemos nós medi-lo na correspondência de D.João de Almeida para o pai, o $1^{\circ}$ Marquês de Alorna. Dizia o filho em 1748: "V. ${ }^{a}$ Exa é o herói do século e tanto mais herói em fazer o milagre de suprir com a sua pessoa os dois móveis principais da guerra que são o dinheiro e a gente. Esta é também o voz do povo e por consequência a de Deus e neste caso julgue $V .{ }^{a}$ Exa os ardentes desejos que eu terei de participar da glória que V. Exa tem alcançado» 43 .

Em sintese, a primeira e hereditária elite social do regime brigantino era basicamente constituída por "militares». Entenda-se por tal, detentores de ofícios superiores no aparelho militar da monarquia. Com efeito, como tem vindo a demonstrar insistentemente Fernando Dores Costa, em parte pela ausência até tarde de instituições de formação especializada, os seus conhecimentos na "arte da guerra" eram em regra limitados, repousando em larga medida a sua capacidade de chefia na autoridade "natural» que a sua qualidade de nascimento thes conferia, habilitando-os para actuarem como medianeiros na mobilização militar, no recrutamento, e no enquadramento de militares experientes de inferior estatuto social ${ }^{44}$.

A persistência de outras práticas institucionais ilustra de forma exemplar, também, a permanência de referentes tradicionais e a dimensão cada vez mais eufemística que estes tendiam a revestir. Vejamos o caso da concessão de senhorios. Quando a coroa concedia um senhorio de direitos reais, com ou sem jurisdição, mas com os respectivos direitos de foral, estava longe de fazer uma doação puramente honorífica, na maior parte dos casos. Quando D.Miguel doou em 1829 ao seu médico, o 1Visconde de Queluz, o riquíssimo senhorio de Cantanhede, desde o século XIV na posse dos Menezes tronco da casa dos Conde de Cantanhede/Marqueses de Marialva, estava a conceder-Ihe uma renda de muitos contos (pouco menos de uma dezena no principio do século) ${ }^{45}$. No entanto, muitas vezes não era esse 0 caso. 
46

Cf. António Vasconcelos de Saldanha, As capitanias do Brasil. Antecedentes, desenvolvimento e extinção de um fenómeno atlântico, $2^{\text {a ed. }}$. Lisboa, CNCDP, 2001

47

Cf. os excertos republicados com actualização ortográfica das "Notícias de Portugal" (1655) em António Sérgio, Antologia dos economistas portugueses (Século XVII), Lisboa, Ed. Sá da Costa, 1974, p.151.

48

Cf. Ana Cristina Nogueira da Silva, 0 modelo espacial do Estado Moderno. Reorganização Territorial em Portugal nos Finais do Antigo Regime, Lisboa, Ed. Estampa, 1998.

\section{9}

Uma realidade bem exemplificada pela casa de Bragança antes da sua entronização cf. Mafalda Soares da Cunha, A Casa de Bragança (15601640). Práticas senhoriais e redes clientelares, Lisboa, Ed. Estampa, 2000; e ainda idem, "Nobreza, casas senhoriais e Expansão: um campo de observação das dinâmicas sociais (século XV-1640)", comunicação apresentada ao colóquio Perspectivas da Historiografia Luso-Brasileira: Agenda do Milénio, S. Paulo, 25-27 de Setembro de 2000

\section{0}

Cf Nuno G. Monteiro, 0 Crepúsculo..., Parte III, capitulo 7, e António Vasconcelos de Saldanha, op. cit.
$\mathrm{Na}$ verdade, um dos atributos nobiliárquicos superiores era, desde 0 período medieval, o exercício de competências jurisdicionais. Os «senhores de terras com jurisdição", como de resto uma parte dos alcaides-mores das terras, constituiam parte integrante da primeira nobreza do reino e deviam, pelo simples facto de o serem, ser convocados para as assembleias do Braço da Nobreza nas Cortes, de acordo com o modelo tradicional pelo qual se realizaram em Portugal até 1697-98 (e depois novamente em 1828). Depois da Restauração, a coroa foi muito parca na concessão de senhorios jurisdicionais: no reino, o seu número global diminuiu drasticamente entre 1640 e o início do século XVIII, como resultado de se terem concedido muito menos senhorios desse tipo do que aqueles que se foram extinguindo. No contexto do império e das ilhas atlânticas, houve até uma política deliberada e relativamente continuada de incorporação na coroa das capitanias de donatários da coroa, as quais no plano jurisdicional tinham virtualmente desaparecido no último terço do século XVIII 46 . Ao longo desse período assistiu-se, claramente, a uma perda da dimensão "territorial» do poder nobiliárquico.

No entanto, apesar do que se disse, quando se elevavam as casas nobiliárquicas à titulação ou a um título mais elevado houve geralmente a preocupação de thes conceder em simultâneo um senhorio jurisdicional, quando aquelas os não tinham, o que se verificou muitas vezes. De resto, durante a dinastia de Bragança, pelo menos, existiu mesmo a figura da doação pela coroa a alguns fidalgos do direito a "fazer vila de (100 ou 200) vizinhos", sem se precisar a povoação, ficando algumas vezes a mercê por concretizar, ou só se verificando muitas décadas mais tarde. Correspondiam estas doações ao enaltecimento das virtualidades da colonização senhorial, defendida enfaticamente por Severim de Faria, já em meados do século XVII, como solução para o problema da desertificação do Sul 47 . Aliás, ao longo do periodo moderno este foi um dos principais motivos que levou à criação de novas vilas. Ainda no final do Antigo Regime estes casos foram numerosos. Para referir apenas casos plenamente consumados, refira-se os de Oeiras (Estremadura), Lapa (Beira), Paialvo (Estremadura), Vila Nova de Souto del Rei (Beira), Bertiandos (Minho), Manique (Estremadura), Abrunhosa (Beira), Vila Nova do Príncipe Regente (Alentejo), e Lanhazes (Minho). Muito frequentemente, tratavam-se de terras onde as casas exerciam algum tipo de direito de propriedade, onde tinham quintas ou herdades e que passavam a ter também uma câmara. Foi o que se passou com Manique do Intendente, uma câmara maioritariamente composta pelos dependentes da propriedade estremenha possuida pelo famoso Intendente Geral de Polícia Diogo Inácio de Pina Manique e seus sucessores, ou na terra de Tolões, comprada pelo financeiro Gaspar Pessoa Tavares na desamortização de 1798, da qual recebeu o senhorio, mas onde nunca chegou a existir câmara.

Na passagem do século XVIII para o século XIX e depois das reformas de 1790/92 (que suprimiram os ouvidores dos senhores ${ }^{48}$ ), num contexto em que o exercício de funções jurisdicionais já não tinha a importância de outros tempos ${ }^{49}$, tanto na metrópole como nos territórios coloniais 50 , a relevância destas concessões régias residia, sobretudo, no estatuto que conferiam e não em recursos ou modalidades de exercício periférico do poder. Depois e imediatamente abaixo de um título, intitular-se senhor de uma terra era uma distinção que conferia uma graduação nobiliárquica, evocativa de outros tempos, e mantinha a sua eficácia simbólica e social, independentemente do seu exercício prático. Mais ambíguo era então o 
51

Embora o assunto mereça uma inquirição mais completa.

52

Cf. Jose Barbosa Canaes de Figueiredo Castelo Branco, Arvores de costados das familias nobres dos reinos de Portugal..., tomo II, Lisboa, 1831

\section{3}

Carlos da Silva Tarouca, "Correspondência entre o Duque Manuel Teles da Silva e Sebastião José de Carvalho e Mello", Lisboa, Anais da Academia Portuguesa de História, Lisboa, $2^{\text {a }}$ série, n6, 1955, p.327 (ortografia actualizada).
54

Não ignorando o epíteto de "manhas" com o qual António Hespanha classifica as invocações dessas dimensões; cf. "Categorias...», p.825. estatuto de alcaide-mor, cuja extensão aos municípios do Brasil, algumas vezes solicitada, não parece ter sido muito ampla 51 .

A tal ponto os ecos do antigo estatuto de "senhor de vassalos" se mantiveram até tarde, que podemos encontrar marcas da sua contaminação semântica em múltiplas e geograficamente diversificadas áreas. Na zona do reino onde a herança da cultura fidalga antiga era mais persistente, a província do Minho, não apenas se multiplicaram até bem dentro do século XIX as reproduções tardias das torres medievais, como na mesma altura a generalidade dos membros da nobreza local se auto-intitulavam "senhor da casa de», embora isso nada mais significasse senão a posse de uma casa, eventualmente armoriada ${ }^{52}$. Mesmo nas distantes paragens do Brasil, a designação "senhor de engenho» não deixa de ecoar as marcas desse referente remoto.

Ė certo que a concessão de sesmarias era uma recurso que persistiu até ao século XIX, e que distinguia claramente o contexto brasileiro do reinol. Mas aquilo que Ihes podiam sobejar em vantagens materiais, faltavaIhes em prestígio. Nunca parecem ter sido aplicadas as propostas, como que de um retorno ao século XVI, feitas em meados do século XVIII pelo Duque Teles da Silva ao futuro Marquês de Pombal: "Para ter mais ligado o Brazil ao Reino, dissera eu, que sua Magestade faria utilmente, gratificando essas principais famílias de muitas terras, senhorios, feudos e comendas, limitando desde agora, com boa advertência para futuro a respectiva extenção" 53 . Note-se que, se os tais senhorios se não concederam, a existência das «principais famílias» na colónia parecia ser um ponto assente...

\section{Representações, ambivalências e eufemismos}

No entanto, a necessária visualização das hierarquias e dos poderes, a perene tendência para a sua teatralização, não consente qualquer ilusão de transparência. Cristalizadas numa herança secular, a ordem social e institucional e as elites dominantes que a corporizavam não deixavam, por isso, de sofrer evoluções e mudanças. Simplesmente, estas tinham de ser legitimadas pela invocação das velhas classificações e designações. Ao contrário da célebre frase do Leopardo de Tomaso de Lampedusa, era necessário que as velhas palavras permanecessem, em particular, quando as coisas e as relações sociais se modificavam. Designadamente, o efeito mais indiscutível da cultura politica do Antigo Regime sobre os trajectos de mobilidade social, por exemplo, era a tendência de imposição de velhas classificações para as mudanças de estatuto, cada vez mais institucionalizadas e reguladas pelo direito ao longo da época moderna, tanto em Portugal como nas suas "conquistas".

As classificações e os signos de distinção mais prestigiosos devem, assim, ser encarados como objectos passiveis de diversas e contrapostas apropriações sociais e individuais. Ao invés de comportamentos uniformes, prestavam-se, afinal, a usos diversificados 54 .

Alguns exemplos e estratégias desta realidade merecem especial destaque. É o caso da ficção do tempo (e do parentesco). Exactamente porque a antiguidade tinha um peso irredutível na sustentação da nobreza, havia que inventá-la, estabelecendo-se vínculos de parentesco com remotos fundadores de linhagens. 0 cartório da nobreza e as provas necessárias para a obtenção de uma carta de brasão de armas aí estão para o comprovar. Todos os investigadores que se debruçaram sobre o assunto acabaram por chegar a uma conclusão idêntica: como se afirmava numa fonte coeva, "no 
55

IAN/TT, Desembargo do Paço, Corte, maço nº $2117, n^{\circ} 78$.

56

Cf. bibliografia citada na nota (15)

57

Luis da Silva Pereira Oliveira, Privilegios da nobreza, e fidalguia de Portugal,cit., pp.53 e 63.

58

Op. cit., p.182.

59

L. Stone, "Social mobility in England, 15001700", Past and Present, Londres, n³3, 1966, p.17.

60

Citada em geral em Nuno G. Monteiro, "Elites locais e mobilidade social em Portugal nos finais do Antigo Regime», in Elites e poder..., pp.37-81.

61

Neste aspecto me demarquei há muito das teses da obra fundadora para o estudo das elites municipais que foi o livro de Maria Helena Coelho e Joaquim Romero de Magalhães, 0 poder concelhio: das origens às cortes constituintes, Coimbra, Centro de Estudos e Formação autárquica, 1986.
Reino muitos homens obscuros adoptam apelidos de Casas, não só ilustres, mas titulares» 55 , desde que o pretendente e seus próximos ascendentes vivessem nobremente, não era difícil a obtenção de uma carta de brasão de armas que o reconhecia como descendente de uma das linhagens nobres conhecidas do reino. Para tal, bastava inventar uma remota ascendência num membro da linhagem do apelido (sobrenome). Em regra, essas ficções eram aceites pelo cartório da nobreza 56 .

0 exemplo antes citado das ordens militares, por outro lado, ilustra bem como a relação entre as classificações e as funções foi-se revelando, em muitos casos cada vez mais difusa e eufemística. Em pleno século XIX continuavam, com efeito, a armar-se freires das ordens militares, que já não eram propriamente freires, nem cavaleiros, nem militares.

No que se refere à governança dos municípios, aplicava-se em Portugal a regra de que "os ofícios nobres, e costumados, a andar em pessoas de esclarecido nascimento, se alguma vez forem conferidos pelo Príncipe em outras de menos condição (...) nobilitam a quem o serve». A legislação seiscentista era explícita em determinar que «não sejam admitidos na governança (...) mecânicos, nem peão algum (...) se não Nobres das partes, e qualidades para isso, e filhos de nobrem 57 , embora os juristas discutissem se tais normas se aplicavam à gente da "governança» (juízes ordinários, vereadores, procuradores e almotacés) de todas as oito centenas de câmaras do país, ou apenas aos das "cidades e vilas notáveis». Os ofícios da governança dos municípios conferiam, assim, nobreza, incompativel com os ofícios mecânicos, que se definiam por dependerem «mais do trabalho do corpo, que do espírito»58. A distinção essencial nobre/mecânico, adoptada em Portugal, pelo menos, desde finais do século XVI, como se disse, acabou por se traduzir no facto da identificação entre ser nobre e viver como tal ("viver à lei da nobreza») se encontrar juridicamente sancionada, podendo ser invocada como prova. Retomando algumas sugestões de um texto clássico de L. Stone ${ }^{59}$, podemos afirmar que o processo antes descrito corresponde à valorização, desde os finais da Idade Média, do status atribuido a boa parte dos grupos ocupacionais (juristas, oficialato, negociantes, etc.) situados fora das categorias sociais de referência da sociedade rural de raiz medieval. Naturalmente, essa banalização da nobreza implicou que se desenhassem múltiplas e diversificadas fronteiras de estatuto no seu interior.

A imensa bibliografia recente sobre 0 assunto 60 tem acentuado a cristalização das elites municipais ao longo dos séculos XVII e XVIII. No entanto, a verdade é que estas se pautavam por uma enorme diversidade quanto ao seu recrutamento social, variando notoriamente de umas terras para outras. Há dois aspectos dessa realidade que, de resto tendem frequentemente a passar despercebidos. As elites municipais constituiam, sem dúvida, uma categoria institucional exatamente porque compartilhavam as mesmas competências, mas não configuravam uma mesma categoria social, precisamente porque era muito o que as diferenciava umas das outras (podiam ser fidalgos da casa real ou simples lavradores ou negociantes). Não havia no reino, por isso, uma "gentry" à inglesa 61 , no sentido de uma categoria social que assumisse idêntidos valores e padrões de vida. Por maioria de razão, embora abrangidos pelo espectro amplo de privilégios nobiliárquicos, pouco havia de comum entre os diversos grupos que deles se beneficiavam. Um grande do reino e um lavrador abastado da governança de um município qualquer não se apreendiam como parte de uma mesam categoria social, embora se distanciassem do vulgo e o sistema de valores sobre os 
62

É esse o argumento essencial do texto antes citado, Nuno G. Monteiro, "Notas sobre a nobreza...".

\section{3}

Cf. vários exemplos no Abade de Baçal, Memórias Arqueológico-Históricas dos Distrito de Bragança, tom.V, "Os Fidalgos», 2a ed., Bragança, reed. Museu Abade Baçal, 1981.

64

Cf. Nuno G. Monteiro, fontes utilizadas para a Parte III de 0 Crepúsculo..., cit..

65

José Veiga Torres, «Da repressão religiosa para a promoção social», Revista Crítica das Ciênciais Sociais, Coimbra, n40, 1994, pp.109-135.

\section{6}

Cf. o estudo clássico de Charles Boxer, Portuguese Society in the Tropics. The Municipal Councils of Goa, Macao, Bahia and Luanda, Madison, The University of Wisconsin Press, 1965.

\section{7}

Cf. _entre muitos outros: Maria de Fátima Gouveia, "Os homens da governança do Rio de Janeiro em fins do século XVIII e início do XIX", in O Municipio no Mundo Português, Funchal, Região Autónoma da Madeira, 1998, pp.545562; Maria Fernanda Bicalho, "As câmaras ultramarinas e o governo do Império», in J. Fragoso, M. F. Bicalho e F. Gouveia (orgs.), O Antigo Regime nos Trópicos..., pp.189-221; idem, "Elites locais: a nobreza da terra e o governo das conquistas. História e historiografia», in Nuno G. F. Monteiro, Pedro Cardim e Mafalda Soares da Cunha (coord.), Optima Pars..., pp.73-97; João Fragozo, "Potentados coloniais e circuitos imperiais: notas sobre uma nobreza da terra, supracapitanias, no Setecentos", in idem, pp.133-168.

\section{8}

Fernanda Bicalho, "Elites locais...", p. 97.

\section{9}

Carlos da Silva Tarouca, "Correspondência entre o Duque Manuel Teles da Silva e Sebastião José de Carvalho e Mello», cit., p.315; citação destacada em primeira mão por K. Maxwell, $A$ devassa da devassa. A inconfidência mineira: Brasil e Portugal 1750-1808, 2a ed., Rio de Janeiro, Paz e Terra, p. 21. quais tenho falado constituísse a referência remota de todas as elites. Em Portugal não havia uma nobreza, mas distintas nobrezas. ${ }^{62}$

Além disso, os citados trabalhos permitem perceber que houve sempre vias de ascensão e ingresso. Uma das mais importantes foram os ofícios das ordenanças que conferiam um enorme poder social, hipóteses de promoção interna e, até, de acesso à elite dos vereadores, pelo menos nas terras menos selectas. Falta-nos um estudo global sobre o tema, mas pensamos que, embora tais cargos tendessem para a hereditariedade em muitos casos 63 , eram requisitados de forma dominante por quem buscava influência local e, também, estatuto social. Com efeito, conferiam um título (capitão-mor, sargento-mor ou capitão das ordenanças) de validade geral, ou seja, que usualmente passava a anteceder o nome de quem o tinha. Sabemos, de resto, que era muito elevado o número de contratadores de rendas das grandes casas nobiliárquicas ou das comendas vagas que desempenhavam ofícios das ordenanças ${ }^{64}$. E conhecemos várias histórias de promoção.

De forma similar, o que se detecta em contextos locais com os ofícios das ordenanças e da almotaçaria, verifica-se à escala do reino com os hábitos das ordens militares e, também, com o grau de familiar do Santo Ofício. De facto, a «pureza de sangue», tal como a divisão entre cristãosnovos e cristãos-velhos, percorriam todos os niveis da realidade social portuguesa, incluindo a alta nobreza, e quase todas as instituições até o periodo pombalino (1768-1773), época em que se aboliram tais distinções e se destruiram os seus registos locais. Precisamente pela preeminência dessa fronteira, o estatuto de familiar do Santo Ofício constituía uma distinção muito procurada, ao ponto de se sugerir, num estudo recente, que essa dimensão se tornou mais relevante do que a repressão na actividade do tribunal a partir do última década de seiscentos, passando esta «da repressão religiosa para a promoção social» 65 .

De acordo com sugestões antigas, designadamente de Charles Boxer66, mas sobretudo de trabalhos recentes 67 , boa parte do que se disse sobre a constituição e mecanismos de estruturação das elites locais no reino pode, com a devida ponderação das especificidades de cada contexto, designadamente, do facto de se terem "gerado numa sociedade escravista" 68 , ser transposto para o espaço das conquistas atlânticas e, em particular, do Brasil. Em larga medida, os parâmetros que balizavam a chamada «nobreza da terra» nas conquistas eram similares aos que encontramos no reino.

Tal como também foi referido, a cultura política do Antigo Regime, era adversa à rápida mobilidade. A matriz corporativa e trinitária da ordem social e jurídica prevalecente, definia uma ordem natural, cuja configuração devia ser imediatamente apreendida, visualisada, ouvida. Esta realidade essencial não impedia a mudança e a mobilidade social, como não bloqueava inteiramente a inovação institucional. Mas exigia que tais processos, para se legitimarem, mantivessem as antigas denominações. Recorde-se a propósito essa espantosa frase que Teles da Silva escreveu a Pombal: «lembro-me de haver nas nossas familiares conversações dito a $V^{a}$ Ex$^{a}$ que quando fossem necessárias algumas grandes disposições novas, sempre lhe quisera pôr nomes e vestidos velhos" 69 . Nesse sentido, há que encarar essas lutas de classificação e os conflitos nos espaços de representação mais destacados - as recorrentes questões de precedências, por exemplo, que tanto podiam ter lugar na corte como numa procissão na mais remota das vilas da província ou das conquistas - como parte essen- 
70

Sem entrarmos aqui numa discussão sobre a definição da esfera do "institucional», neste ponto demarcamo-nos de A. Hespanha, "Categorias...., cit.

71

De algum modo, os trabalhos de F. Olival, Honra, Venalidade e Mercê..., e de Nuno G. F. Monteiro, o Crepúsculo..., constituem ilustrações dessa dupla dimensão.

72

Cf. sobre o assunto a sintese de Nuno G. Monteiro, "Aristocratic Succession in Portugal (16th-19th centuries)", in João Pina Cabral e Antónia Pedroso de Lima (dir.), Elites. Choice, Leadership and Sucession, Oxford, Berg., 2000.

\section{3}

Cf. Nuno Gonçalo Monteiro, "Sociologia das elites locais (séculos XVII-XVIII). Uma breve reflexão historiográfica», in Mafalda Soares da Cunha e Teresa Fonseca (ed.), Os municipios no Portugal Moderno. Dos forais manuelinos à reformas liberais, Lisboa, Ed. Colibri, 2005, pp.59-72.

\section{4}

Para retomar uma expressão feliz de Sérgio Cunha Soares, "Nobreza e arquétipo fidalgo. A propósito de um Livro de Matrículas de filhamentos (1641-1724)", Revista de História das Ideias, Coimbra, FLUC, vol.19, 1998, pp.403-455 cial da afirmação das hierarquias e dos poderes: os poderes que se viam eram os que existiam. Os conflitos pelos lugares visiveis eram, em larga medida, os conflitos mais decisivos, por isso mesmo.

\section{A indisponibilidade e a rigidez da estrutura do espaço social}

No entanto, a insistência nas possibilidades de apropriação, de manipulação e de ambivalência de uma estrutura de classificação com referentes remotos não deve fazer esquecer que esta se encontrava consubstanciada em instituições e em relações sociais que perpetuavam esses modelos com uma existência multissecular 70 .

Ora, essas instituições estavam longe de se revelar fluidas e mutáveis. 0 espaço social caracterizava-se por zonas de porosidade, mas também por espaços de extraordinária rigidez, que nenhuma chave podia abrir.

$\mathrm{Na}$ verdade, pode dizer-se que a evolução, a longo prazo, da estratificação nobiliárquica na monarquia portuguesa, entre os finais do século XVI e o triunfo da revolução liberal em 1832-34, se caracterizou por dois processos simultâneos, mas de sentidos inversos: abertura na base do grupo (acompanhado da restrição progressiva dos seus privilégios gerais), quase até à banalização, e a constituição de uma primeira nobreza do reino, restrita e claramente separada das restantes categorias nobiliárquicas, encimada pela casas da nobreza titular ${ }^{71}$. A clivagem entre a principal nobreza da corte, encimada pelos Grandes, e as restantes nobrezas, revela-se decisiva para a análise de todos os processos sociais. A hierarquia social da monarquia percorria todo o seu espaço institucional e não se confundia linearmente com a das distâncias geográficas. Desse ponto de vista, por exemplo, um fidalgo da casa real da governança da Bahia, no Brasil, tinha precedência sobre um simples nobre da câmara de Ourique, no Alentejo.

Para quase todos, porém, o acesso à primeira elite da monarquia tornarse-ia pouco menos do que impossivel. Com poucas excepções conhecidas, não houve riqueza nem ficção genealógica que chegasse, durante mais de uma centena de anos, para abrir as portas do topo da pirâmide nobiliárquica, que monopolizava os mais destacados ofícios da monarquia. Ao mesmo tempo, os destinos individuais, praticamente definidos à nascença, adquiriram dentro da primeira nobreza do reino uma rigidez inusitada imposta pela disciplina da casa e pela obrigação de servir a monarquia entre meados de seiscentos e o último terço de setecentos. 0 morgadio peninsular e, em particular, o português, era muito mais do que uma forma de transmissão de bens entre gerações: constituia um verdadeiro código de conduta, que se impunha como referência aos grupos aristocráticos e a todos aqueles que procuravam reproduzir os seus comportamentos ${ }^{72}$. A rigidez de uma zona bem definida do espaço social era indissociável da rigidez da disciplina familiar, que condicionava o casamento e o celibato e fazia equivaler este para as mulheres, como para muitos filhos segundos, às carreiras eclesiásticas; a profusão de casas religiosas era, por isso, uma quase condição da sua aplicação.

No reino, essa apertada disciplina familiar foi esforçadamente reproduzida, embora com menor eficácia, não por todas as elites locais, mas pelo seu segmento superior, o qual podemos designar de principal fidalguia das provincias $^{73}$. Na verdade, tal como os brasões de armas e alguns outros elementos, 0 "modelo reprodutivo vincular» era parte integrante e essencial do "arquétipo fidalgo" 74 do reino, pelo menos até finais do século XVIII, quando aquele começa a dar sinais de erosão. Pelo contrário, parece que essa componente, pelo menos no que se refere à primogenitura e à instituição de morgados, 
75

Cf. Mafalda Soares da Cunha e Nuno G.F. Monteiro, "Governadores e capitães-mores do império Atlântico português nos séculos XVII e XVIIII, in Nuno G. F. Monteiro, Pedro Cardim e Mafalda Soares da Cunha (coord.), Optima Pars. Elites Ibero-Americanas do Antigo Regime, passim. nunca se impôs de forma análoga no Brasil. Matéria que merece, certamente, uma ampla reflexão.

Uma clara tradução da polarização entre a "primeira nobreza da corte» e as restantes elites, pode encontrar-se na selecção e recrutamento dos vicereis, governadores gerais e governadores das capitanias do império português ao longo dos séculos XVII e XVIII, que estudámos recentemente. Com efeito, verificamos ai um claro processo de aristocratização ou elitização dos recrutados, visivel quer nas principais capitanias, quer na esmagadora maioria das capitanias subordinadas. Ao invés de algumas imagens correntes associadas ao "século das Luzes", o que detectamos é um peso crescente da "qualidade do nascimento", em detrimento de outros critérios de escolha. No Brasil tomado como um todo, os descendentes de titulares, da primeira nobreza de corte e de fidalguia inequívoca passaram de $20 \%$ dos nomeados no século XVII para 45\% no século XVIII. E, nas capitanias não dependentes subiram de $57 \%$ para 82\%. Nos outros governos principais do Atlântico, a tendência para a aristocratização foi igualmente a nota dominante: Angola (que subiu de 71\% no século XVII para 95\% no século XVIII), Madeira (de 61\% para 85\%) e Mazagão (de 91\% para 80\%, apenas por causa dos interinos) foram governos fidalgos, tal como o novo dos Açores (100\%). No mesmo sentido, detectámos uma clara redução do número de "brasílicos» ou brasileiros e naturais das terras nomeados. Na América portuguesa a percentagem total dos naturais desceu de 22\% no século XVII para apenas 10\% no século seguinte. Entre 1700 e 1810, os naturais da terra representaram 3\% dos nomeados nas capitanias principais quando antes alcançavam $27 \% 75$.

A principal fidalguia do reino, que se reputava depositária do ethos ancestral da nobreza portuguesa, constituia, no fim de contas, o reduto da maior cristalização. E a crise da instituição vincular e dos padrões de comportamento familiar acompanharam de perto os primeiros sintomas de crepúsculo do grupo.

Uma pequena nota acerca do percurso biográfico, recentemente estudado, desse personagem central, do periodo da crise Antigo Regime na monarquia atlântica portuguesa, que foi D.Rodrigo de Sousa Coutinho ilustra exemplarmente o que antes se disse, com a particularidade de se reportar já a uma etapa tardia. Seu pai, o célebre D.Francisco Inocêncio, governador de Angola e diplomata em Madrid, era filho segundo de uma singularíssima casa da primeira nobreza do reino, a dos senhores e (passados e futuros) condes de Alva. Esta casa juntava, com efeito, a varonia ilustre da casa dos Sousa/condes do Redondo, na qual nascera como filho não sucessor o avô de D.Rodrigo, com o imenso capital económico acumulado por uma das famílias que se destaca por sua ascensão social e política no século $\mathrm{XVII}$, a dos Monteiros - juizes da inconfidência e muitas coisas mais -, dos quais fora finalmente sucessora a avó paterna de D.Rodrigo. Acontece que D.Francisco, como filho segundo não quis seguir a carreira eclesiástica mas a das armas, pelo que teve de procurar capital económico para se poder casar pela primeira vez. Veio a encontrá-lo consorciando-se em 1748 com Ana Joaquina Luísa Teixeira de Andrade, filha de um militar transmontano, que chegou a mestre da campo e a fidalgo cavaleiro da casa real. Porém, a fortuna e os ulteriores imbróglios não vinham daí, mas da ascendência da avó materna de D.Rodrigo: filha de um minhoto, Matias Barbosa da Silva, e de sua mulher com raizes inequivocamente "mecânicas», que emigrou, em 1699, para o Brasil e acumulou enorme fortuna e cargos na fazenda e outros em Minas Gerais no periodo áureo. Nem D.Rodrigo nem outros contemporâneos 
76

Cf. Luiz de Mello Vaz de São Payo, "Indevida admissão na Ordem de Malta: D.Francisco Mauricio de Sousa Coutinho", Filermo, Lisboa, v.3, 1994, pp. 83-100.

77

Andrée Mansuy-Diniz Silva, Portrait d'un homme d'État: D.Rodrigo de Sousa Coutinho, Comte de Linhares 1755-1812, I - Les années de formation, Lisboa-Paris, F. C. Gulbenkian, 2002, pp. 211-212, ortografia actualizada.

78

Idem, ibidem, p.30

79

Sobre o assunto, cf. Pedro Calmon, História da Casa da Torre. Uma dinastia de pioneiros, $2^{\mathrm{a}} \mathrm{ed.}$ Rio de Janeiro, José Olympio, 1958, pp. 82 e seg., e Erivaldo Fagundes Neves, Uma comunidade sertaneja: da sesmaria ao minifúndio (um estudo de história regional), Salvador, EDUFBa/ Feira de Santana, Univ. Estadual de Feira de Santana, 1998, pp.60 e seg. (agradeço as referências a Mónica Dantas e Rodrigo Ricupero).

80

D. António Caetano de Sousa, Memórias Históricas e Genealógicas dos Grandes de Portugal, 4a ed. (1a de 1755), Lisboa, 1933, p.240.

81

Mas nunca como o único. No século XVI a casa de Bragança, tal como algumas das outras grandes casas, faziam fidalgos e comendadores, privilégio que aquela prolongou até à sua entronização em 1640 (cf. Mafalda Soares da Cunha, A casa de Bragança..., Cit.). E depois subsistiram, como antes se sugeriu, vários outros dispositivos concorrentes (desde logo, a genealogia). seus puderam esquecer a mácula que estava subjacente ao seu património brasileiro, embora, em 1794, um seu irmão tenha conseguido passar com uma ascendência falsificada nas exigentes habilitações da muito fidalga Ordem de Malta (fez-se passar por bisneto de Matias Barbosa, senhor de engenho, fidalgo da casa real e natural da Bahia)76. Em 1786, na sequência das dificuldades de promoção de seu irmão, José António, na Sé Patriarcal, o futuro ministro do Príncipe D.João referiu-se explicitamente em carta a Martinho de Melo e Castro à «vox publica de Lisboa (...) dizendo que isto nasce de ele não ter nascimento correspondente àquele lugar» e a "que a exclusão que se pode dar a meu irmão só pode nascer de minha avó e de minha mãe»; acrescentando, entre muitas outras considerações, que "de inferiores alianças se não livram aquelas mesmas familias que se quiseram fazer conhecidas pelo ridículo epiteto de Nobilissiması ${ }^{77}$. Por mais surpreendente que pareça, não se pode entender o percurso do personagem se não se tiver em conta que, apesar do "Dom» e da varonia de um bisneto de Grande do Reino com remotos ascendentes ilustres, na penúltima década de setecentos uma mácula de mecânica "brasileira» próxima não se apagava facilmente na primeira nobreza do reino. Apesar das diatribes pombalinas contra o "arbitrio dos Genealógicos», estes nunca deixaram de se poder instituir como um centro de resistência.

A história que acabamos de citar acaba por se cruzar, a dado momento, com uma outra, provando que o estigma dos casamentos «brasileiros» na primeira nobreza da corte se podia estender mesmo aos mais destacados de todos os conhecidos: os de Joana da Silva Guedes de Brito. As famosas alianças matrimoniais desta senhora são invocadas por uma das testemunhas arroladas em 1760 num acto notarial pelos pais de D.Rodrigo; afirmava a referida testemunha a propósito da mãe deste que «muitas senhoras ainda de menor qualidade que a justificante, tendo cabedais, têm casado com pessoas grandes, como foi Dom João de Mascarenhas, filho do Conde de Coculim, que casou com D. Joana Guedes de Brito, filha do coronel António da Silva, senhor de engenho, e ficando viúva sem sucessão se casou com um fidalgo da casa dos Saldanhas »78. Ao contrário do que se dizia, a história em questão 79 não era uma entre muitas: nem pela "qualidade» do noivos reinois, nem pela imensidão da fortuna brasileira. São os únicos casamentos «brasileiros» destacados por D.António Caetano de Sousa, que se refere à dita D. Joana sublinhando sempre o facto de ser «therdeira de uma grande fazenda naquele Estado» 80 . Antes do início do século XIX, este caso foi mesmo excepcional.

\section{A monarquia como regulador e centro de poder}

A ascensão na hierarquia nobiliárquica podia fazer-se, até certo patamar, pela riqueza - podem-se incluir as alianças matrimoniais, para os efeitos agora considerados, como uma forma de acumulação de capital económico - e pelo modo de vida. Mas, dai para cima e de forma progressivamente mais apertada, quase só pelo serviço ao rei. Em geral, estes eram mesmo dois momentos distintos nas trajectórias das famílias ao longo de várias gerações.

A monarquia instituia-se, assim, como o regulador fundamental no acesso aos diversos graus de nobreza ${ }^{81}$. Essa dimensão constituía um vector decisivo que conferia à monarquia uma centralidade incontornável e a transformava num factor decisivo da coesão social e política de todo o imenso espaço pluricontinental por ela tutelado. Nessa matéria, existia sem discussão um centro político e muitas periferias, nas quais se devem incluir as conquistas. Desde a nomeação para os ofícios superiores da monarquia até ao 
82

Destaque-se apenas que a "base material» da principal elite do reino se diferenciava radicalmente das, de resto variáveis, que sustinham as elites das conquistas. 0 impacto das rupturas políticas a esse nivel foi, por isso, muito diferente dos dois lados do Atlântico. provimento de um ofício local de nomeação régia, passando pelos hábitos das ordens, a que antes nos referimos, o recurso à regulação do centro constituía um requisito quase universal: os milhares de requerimentos das várias repartições da administração central que, apesar de todas as vicissitudes e destruições, chegaram até nós ai estão para o comprovar.

Nesse sentido, a distância geográfica era um dos muitos factores que acentuavam o desfasamento institucional em relação ao centro. 0 afastamento face aos círculos da corte era algo que as nobrezas locais do reino partilhavam com as das conquistas.

No entanto, o centro político não deve ser confundido com o "governo", no sentido moderno da palavra. Da "grande política», que passou ao longo de setecentos da esfera das consultas do Conselho de Estado, no início do reinado de D.João $V$, para a dos Secretários de Estado, na segunda metade do século, sempre antes da régia assinatura, só fazia parte a nomeação de pessoas para os cargos e ofícios superiores e a remuneração dos respectivos serviços, para além, como é evidente, de outras matérias, com as relações externas à cabeça. A politica de mercês constituía mesmo o grosso do expediente de muitas repartições, nas quais se acumulavam pareceres sobre as nomeações para os mais diversos oficios superiores e os despachos sobre remuneração de serviços. Tirando casos especiais, as mercês de menor monta eram decididas em outros níveis. Ou seja, também no plano das instâncias de deliberação, a política de mercês obedecia a uma lógica dual: muito restritiva no topo até finais de setecentos, mais aberta na base.

Como antes se referiu, o «rei distante», o desfasamento geográfico era um dos muitos elementos que configuravam as relações entre o centro e a periferia da monarquia portuguesa. Mas de modo algum o único, nem o mais decisivo. Muito se escreveu sobre os efeitos da transferência da corte de Lisboa para o Rio de Janeiro em 1807-1808. Não é este o lugar para o discutir. Para lá se deslocaram, em dados momentos, cerca de metade dos representantes das casas da primeira nobreza da corte. E , no entanto, foram escassos os títulos concedidos a naturais da colónia (caso notório o da 1a Baronesa de S.Salvador do Campo de Goiatacazes, 1812) e nenhum o recebeu com grandeza. Mais decisivo ainda, foi o facto das alianças matrimoniais entre a primeira nobreza do reino e naturais do Brasil se contarem pelos dedos. De resto, a nobreza titular do império brasileiro, ulteriormente elevada, tinha limitadissimas conexões familiares com a primeira nobreza do reino. Nesse plano, a monarquia portuguesa do Antigo Regime manteve-se até ao fim prisioneira dos compromissos assumidos pela dinastia no contexto da guerra da Aclamação de 1640-1668. Os seus sucedâneos no Brasil, depois de 1822, e em Portugal, a partir de 1832-34, fazem já parte de uma outra história 82 . 